Patient-centered care

July 2014

Practice Matters

Title/Key concepts in providing patient-centered care

By Aaron Bechtold, BSN (STUDENT) and Suzanne Fredericks, PhD, RN

In patient-centered care, the patient's values, beliefs, and preferences regarding overall health and wellbeing are incorporated into the plan of care and implementation of all care-related activities. Most nurses are familiar with the concept of patient-centered care but may not know how to integrate this concept effectively into practice. This article presents an overview of patient-centered care and explains how to integrate it clinically, focusing on specific strategies. To apply patient-centered care to your clinical practice, you need to consider the five essential concepts below.

\title{
/H1/1: Respect
}

Encourage patients to share their values, preferences, and needs related to health care on the initial assessment, because these will form the basis of the overall plan of care. Custom care to the individual patient, ensuring that it's culturally appropriate. Be aware that patient preferences aren't static, so your care may change based on circumstances.

To acquire the interpersonal and communication skills needed to interact with patients, practice by interviewing a preselected group of patients and audiotaping the interviews. This can help you fully understand the patient's perceptions of the care he or she would like to receive. Before the interview, provide the patient with a clear explanation of reason for the interview, emphasizing that it's strictly for teaching and learning purposes. Also, let patients know their care will not be affected negatively in any way if they choose to not engage in the interview.

Questions to ask during the interview include: What type of care would you like to receive? To what degree do you wish to be involved in your care during your hospitalization? Would you like us to include a family member or other person in the care you'll be receiving? AND IS BEING INVOLVED IN YOUR PERSONAL CARE SOMETHING THAT IS OF VALUE OR OF IMPORANTANCE TO YOU? After the session, you and your colleagues can review the tapes to understand how effectively your practice is incorporating patient-centered care.

\section{/H1/2: Care coordination and integration}

All disciplines involved in the patient's care should be coordinated to heighten the focus on the patient. However, as you probably know, this isn't always possible. To begin this process, work with one member of the care team to design multidisciplinary care that contains elements of patient-centered care. Keep in mind that some multidisciplinary team members may be unfamiliar with patient-centered care; you may need to teach them beforehand or mentor them. As you become more proficient in patient-centered care techniques, you'll gradually develop a more multidisciplinary plan of care for your patient.

\section{/H1/3: Information, communication, and education}

To help patients understand patient-centered care, provide them with key information, communication, and education. Embed elements of patient-centered care into your discussions with patients. FOR EXAMPLE: DURING YOUR CONVERSATION WITH PATIENTS, LET THEM KNOW THAT THE ACTIVITIES THEY WILL BE ENGAGING IN ARE REFLECTIVE OF WHAT THEY INDICATED WERE OF IMPORTANCE TO THEM so they understand the integral role they play in their overall health and well-being. Also, ask them for their help in designing their overall plan of care. Answer patients' answered in easy-to-understand terms. Tailor communication to reflect patients' needs, to 
promote their engagement in the patient-centered care process. To do this, ask open-ended questions to gain insight into their concerns. Examples of open-ended questions include:

- Can tell me how you're feeling right now?

- What would you like me to do for you at this moment?

- Here's a list of SELF-CARE activities that need to be completed before the end of the day.

Make sure you have enough of time available for this interaction, so patients can express their concerns and needs freely. Also, provide opportunities that allow for shared decision-making when it comes to choosing a treatment regimen. Ideally, YOU, THE patient AND OTHER MEMBERS OF THE HEALTHCARE TEAM should discuss pros and cons of various options. Using visual images or analogies can help the patient understand the information you're presenting. Print, AUDIO, VIDEO, AND Internet IN ORDER TO help patients understand their health condition AND MAKE selection of appropriate treatments easier.

Decision aids can enhance patient understanding of treatment options and promote shared-decision making. THEY CAN BE IN THE FORM OF A BOOKLET, AUDIO RECORDING, OR VIDEO AND ENCOMPASS INFORMATION RELATING TO THE PROS AND CONS OF A PARTICULAR TREATMENT. Decision aids help patients grasp clinical information and develop informed preferences. THEY ALLOW PATIENTS TO MAKE INFORMED CHOICES THAT ARE REFLECTIVE OF THEIR VALUES AND BELIEFS. for outcomes they may not be aware of Shared decision making is key to patient-centered care interventions because it puts the patient's values and preferences center stage.

\section{/H1/4: Comfort}

Ensure that the patient is physically and emotionally comfortable to actively engage in patient centered care. ENHANCED COMFORT CAN ENHANCE THE PATIENT CENTERED CARE INTERACTION.

\section{/H1/5: Family input}

If the patient gives consent, incorporate input from family members and friends into the design of the overall plan of care.

When you provide patient-centered care, you're collaborating with patients to ensure that their preferences, values, and beliefs related to care are taken into account. Even though patient-centered care has been well-defined, its integration across the discipline of nursing hasn't been fully actualized. Using the strategies in this article can help you integrate these patient-centered care principles into your daily practice.

\section{/H1/Selected references}

Abraham M, Moretz JG. Implementing patient- and family-centered care: part I - understanding the challenges. Ped Nurs. 2012;38(1):44-7.

Barry MJ, Edgman-Levitan S. Shared decision making - pinnacle of patient-centered care. $N$ Eng J Med. 2012;366(9):780-1.

Berwick DM. What "patient-centered" should mean: confessions of an extremist. Health Aff (Millwood). 2009;28(4):w555-65.

Ford PE, Rolfe S, Kirkpatrick H. A journey to patient-centered care in Ontario, Canada: implementation of a best-practice guideline. Clin Nur Spec. 2011;25(4):198-206.

Hobbs JL. A dimensional analysis of patient-centered care. Nurs Res. 2009;58(1):52-62. 
/Au bio/

Aaron Bechtold is a BSN student at and research assistant at RYERSON UNIVERSITY IN TORONTO, ONTARIO, CANADA.

Suzanne Fredericks is an ASSOCIATE PROFESSOR AT RYERSON UNIVERSITY IN TORONTO, ONTARIO, CANADA.

This manuscript was published by HealthCom, Bechtold, A. \& Fredericks, S. (2014). Key concepts in patient-centered care. American Nurse Today.

http://www.americannursetoday.com/assets/0/434/436/440/11662/11664/11676/11720/7ba8fd15 -971f-4ced-8f20-bdef86a49b79.pdf 